Research Article

\title{
Breast Cancer Increases in Young Age Female in Pakistan
}

\section{Maria Arif*, Anum Zeb², Taha Arif3, Aadil Omer4}

*Corresponding author: Maria Arif

Address: ${ }^{1}$ National University of Sciences and Technology, Islamabad, Pakistan; ${ }^{2}$ National University of Medical

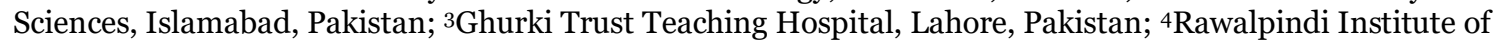
Cardialogy, Rawalpindi

E-mail $\triangle$ Maria.aadil@yahoo.com

Received: 28 June 2019; Accepted: o8 August 2019

\section{ABSTRACT}

Cancer arises from the transformation of normal cells into tumor cells in a multistage process that generally progresses from a pre-cancerous lesion to a malignant tumor (Davis et al., 1964). The aim of the study is to find out reason, which can increases various risk factors of breast cancer among reason of Pakistani women.

Materials and Methods: A total 100 subjects were divided into two groups, 50 subjects in each group. Subjects were interviewed using a specifically designed questionnaire. Subsequent disease-specific mortality was also measured.

Results: In this study, the total 50 sample patients different mean age of the patients is divided into two group $16-40(n=25)$ and $41-75(n=25)$ years. Most of the patients have high grade tumor is Provisional Grade II (32.0\%), Ductal Carcinoma Grade III 11(22.0\%), Fibro-adenoma 10 (20.0\%), Carcinoma 7 (14.0 \%), benign breast disease 2 (4.0\%), giant fibroadenoma1 (2.0\%), Tubular Adenoma Right breast 1 (2.0\%) and consistent with fibro-adenoma 1 (2.0\%). The analysis was study the different types of breast cancer in different age groups. Most frequent categories were Ductal Carcinoma Grade III (22.0\%) and Provisional Grade II (32.0\%).

Conclusions: Pakistani women are at the highest incident rate (about 32.0\%) for breast cancer is diagnosed in stages III and IV. Moreover various risk factors including age, breast-feeding, physical activity and menopausal status were significantly associated with increased risk of developing breast cancer in Pakistani women (Bernstein L, 2002). Women in Pakistan do not know much about that breast cancer is the curable disease. There is strong evidence women that lack of education and low income contribute significantly along with various other factors. We know that breast cancer prevention is in an early diagnosis. When disease is detected early, patient can almost be cured without mutilating surgery like mastectomy, leaving women with less psychological morbidity.

Key Words: Breast cancer; Mammary gland; Mastectomy 


\section{Introduction}

Cancer is a familial diseases and most progressive disease in the world as well as in Pakistan. Most common cancer in female is breast cancer. Breast tissues are made up of milk production glands, which called lobules and the ducts, which connect the lobules to the nipple. The remaining part of the breast is composed with lymphatic, connective and fatty tissues (Hunter, 2000). In Pakistan, the prevalence of breast carcinoma is considerably high. According to Punjab Cancer Registry Report, in 2014 5,521 cases were newly cancer diagnosed; out of which 44.3\% were breast cancer cases (Shaukat Khanum Memorial Cancer Hospital \& Research Center, 2014).An epidemiological study has reported that the incidence of breast carcinoma is alarmingly high in younger females in Pakistan (Shaukat et al., 2013). Every tenth women in Pakistan has a risk of breast cancer during her life (Chattopadhyay et al., 2014). The incidence of cancer rises dramatically with age, most likely due to a build-up of risks for specific cancers that increase with age (Bernstein L, 2002). The overall risk accumulation is combined with the tendency for cellular repair mechanisms to be less effective as a person grows older. Breast carcinoma is due to increase in lifetime exposure to estrogen and progesterone. So that, risks of breast cancer increases in early menarche, menopausal, infertility, first pregnancy over the age of 30 and therapy, like hormone therapy (estrogen with or without progesterone). Oral contraceptives, which contains estrogen and progesterone, also causes a small increased risk of breast cancer in young women (Ferlay et al., 2015). There are two types of carcinogens; chemical carcinogens and biological carcinogens which can cause breast cancer. Chemical carcinogens includes; asbestos, aflatoxin (a food contaminant), and arsenic (a drinking water contaminant) while biological carcinogens includes; infections (like: viruses, bacteria and parasites) (Ferlay et al., 2015).

\section{Material and Methods}

This study was conducted in the Department of Pathology, Army Medical College, National University of Medical Sciences, Islamabad, Pakistan. Informed consent has been taken from the patients. Study has been conducted after the approval from institutional ethical committee. Total number of the subjects was 100 females. Whole subjects were divided into two groups, control $(n=50)$ and breast carcinoma group $(n=50)$. Total period of the study was six months (Jan 2016 to Mar 2016).

The Histopathologist picked the sample in fine $5 \mathrm{~mm}$ needle. Prepare the slide and incubate at $65^{\circ} \mathrm{C}$ for 30 minute. Immerse slide in xylene for 30 minute and repeated new xylene. Slide $100 \%$ ethanol for Io minute repeat the step in new ethanol. Slide in $90 \%$ ethanol for 5 minute and $70 \%$ ethanol for $1 \mathrm{~min} 50 \%$ for $1 \mathrm{~min} 30 \%$ ethanol for $1 \mathrm{~min}$. Rinse in PBS for $5 \mathrm{~min}$. Wipe away excess liquid from around tissue. Hematoxylin solution 20oul and incubate at room temperature for 5 minutes. Wash in running tap water from reverse side. Rinse in PBS for 5 min. Wipe away excess liquid from around tissue. Stain in 40oul Eosine solute for 30sec and wash running tap water from reverse side. Rinse in PBS for 5 minutes. Dehydrate in absolute alcohol two changes for 2 minute. Clear in xylene two change 10 minute of each. Mount the slide was observed under microscope. 


\section{Results}

A total subjects $(n=100)$ is divided into two groups of normal healthy control $(n=50)$ and breast carcinoma group $(n=50)$. Breast carcinoma group were divided into two groups; group A (16- 40years) and group B (41 to 75 years).The mean \pm SD of age of group A and group B was statistically non-significant. The present study revealed Provisional Grade 1116 (32.0\%), Ductal Carcinoma Grade III 11 (22.0\%), Fibro-adenoma 10 (20.0\%), Carcinoma 7 (14.0 \%). benign breast disease 2 (4.0\%), giant fibro-adenoma1 (2.0\%), Tubular Adenoma Right breast1 (2.0\%), consistent with fibro-adenoma 1 (2.0\%) and Fibro-adenosis lump breast 1 (2\%).Statistical analysis was done by using SPSS20. Frequency and percentages of these stages were presented in Table 1. In this study, group A contains Provisional Grade 1 (32.0\%) and Ductal Carcinoma Grade III (22.0\%).

Table 1: Different types of breast cancer.

\begin{tabular}{|l|l|l|l|}
\hline \multicolumn{2}{|c|}{} & Frequency (n) & Percent (\%) \\
\hline \multirow{5}{*}{ Breast Carcinoma (n=50) } & Fibroadenoma LUMP breast & 10 & 20 \\
\cline { 2 - 4 } & benign breast disease & 2 & 4 \\
\cline { 2 - 4 } & giant fibroadenoma & 1 & 2 \\
\cline { 2 - 4 } & Tubular Adenoma Right breast & 1 & 2 \\
\cline { 2 - 4 } & Fibroadenosis lump breast & 1 & 2 \\
\cline { 2 - 4 } & Consistent with fibroadneoma & 1 & 2 \\
\cline { 2 - 4 } & Ductal Carcinoma Grade lll & 11 & 22 \\
\cline { 2 - 4 } & Carcinoma & 7 & 14 \\
\cline { 2 - 4 } & Provisional Grade ll & 16 & 32 \\
\hline
\end{tabular}

\section{Discussion}

Breast cancer is the most frequently diagnosed cancer in Pakistani females (Bhurgri, 2004). The Pakistani population has a large increase in its incidence among Asian countries (Liede et al., 2002). Age is an important risk factor for different cancers (White et al., 2014).In general, reproductive factors, like puberty and breastfeeding have already been revealed to have a protective significance against breast cancer (Bernstein, 2002).

The risk of carcinoma increased as the BMI increased from the normal range. Other studies also found that females with high BMI were at increased risk of breast cancer (Ozmen et al., 2009; Bhaskaran et al., 2014; Xia et al., 2014), which may be mainly due to higher levels of free estrogen produced by excess aromatase activity in the peripheral adipose tissue (Bulun et al., 2012). Further research is recommended to explore the causal mechanisms that how breastfeeding influence breast cancer. Both Pregnancy and breastfeeding reduces the lifetime number of menstrual cycles of a woman and thus her total exposure to endogenous hormones. In addition, breastfeeding and pregnancy also has direct effects on breast cells differentiation and maturation. Differentiated cells are comparatively more resistant to be transformed into cancerous cells (Russo et al., 2005; Britt et al., 2007). Menopause is not directly related to cancer, but actually the risk of developing cancer increases with the increasing age (Surakasula et al., 2014). During the reproductive age of females, the ovaries produce steroid hormones affecting function and development of the breast (Cancer, 2012). Research has showed that marital status 
somehow affects an individual's health but this association has not been studied comprehensively (Costello and Osborne, 2005; Floud et al., 2014). Married women were less likely to have breast cancer (Surakasula et al., 2014). Some other researchers have also reported an association between marital status and multiple cancers. Aizer and colleagues found that unmarried individuals have significantly higher risk of metastatic cancer (Aizer et al., 2013).

\section{Reference}

Aizer AA, Chen MH, Mccarthy EP, Mendu ML, Koo S, Wilhite TJ, Graham PL, Choueiri TK, Hoffman KE, Martin NE. Marital status and survival in patients with cancer. Journal of clinical oncology 2013; 31: 3869-3876.

Bernstein L. Epidemiology of endocrine-related risk factors for breast cancer. Journal of mammary gland biology and neoplasia 2002; 7: 3-15.

Bhaskaran K, Douglas I, Forbes H, Dos-Santos-Silva I, Leon DA, Smeeth L. Body-mass index and risk of 22 specific cancers: a population-based cohort study of 5• 24 million UK adults. The Lancet 2014; 384: 755-765.

Bhurgri Y. Karachi cancer registry data--implications for the national cancer control program of pakistan. Asian Pac J Cancer Prev 2004; 5: 77-82.

Britt K, Ashworth A, Smalley M. Pregnancy and the risk of breast cancer. Endocrine-related cancer 2007; 14: 907-933.

Bulun SE, Chen D, Moy I, Brooks DC, Zhao H. Aromatase, breast cancer and obesity: a complex interaction. Trends in Endocrinology \& Metabolism 2012; 23: 83-89.

Chattopadhyay S, Siddiqui S, Akhtar MS, Najm MZ, Deo S, Shukla N, Husain SA. Genetic polymorphisms of ESR1, ESR2, CYP17A1, and CYP19A1 and the risk of breast cancer: a case control study from North India. Tumor Biology 2014; 35: 4517-4527.

Costello $\mathrm{AB}$ and Osborne JW. Best practices in exploratory factor analysis: Four recommendations for getting the most from your analysis. Practical assessment, research \& evaluation 2005;10: 1-9.

Das U, Lakshmaiah K, Lokanatha D, Babu GK, Jacob L, Babu S. Breast Cancer in Women of Younger than 35 Years: A Single Center Study. Journal of Molecular Biomarkers \& Diagnosis 2015; 6: 1.

Davis H, Simons M, Davis J. Cystic disease of the breast: Relationship to carcinoma. Cancer 1964; 17(8): 957-978.

Floud S, Balkwill A, Canoy D, Wright FL, Reeves GK, Green J, Beral V, Cairns BJ. Marital status and ischemic heart disease incidence and mortality in women: a large prospective study. BMC medicine 2014; 1: 12.

Hunter CP. Epidemiology, stage at diagnosis, and tumor biology of breast carcinoma in multiracial and multiethnic populations. Cancer 2000; 88: 1193-1202.

Liede A, Malik IA, Aziz Z, De Los Rios P, Kwan E, Narod SA. Contribution of BRCA1 and BRCA2 mutations to breast and ovarian cancer in Pakistan. The American Journal of Human Genetics 2002; 71: 595-606.

Ozmen V, Ozcinar B, Karanlik H, Cabioglu N, Tukenmez M, Disci R, Ozmen T, Igci A, Muslumanoglu M, Kecer M. Breast cancer risk factors in Turkish women-a University Hospital based nested case control study. World Journal of Surgical Oncology 2009; 7: 37.

Russo J, Mailo D, Hu YF, Balogh G, Sheriff F, Russo IH. Breast differentiation and its implication in cancer prevention. Clinical Cancer Research 2005; 11: 931s-936s.

Shaukat U, Ismail M, Mehmood N. Epidemiology, major risk factors and genetic predisposition for breast cancer in the Pakistani population. Asian Pacific Journal of Cancer Prevention 2013; 14: 5625-5629.

Glob J Cancer Case Rep

http://www.cancercasereports.com/ 
Global Journal of Cancer Case Reports | August 2019 | Volume 01| Issue 01 | Page 1-5 Arif M., Breast Cancer Increases in Young Age Female in Pakistan

Surakasula A, Nagarjunapu GC, Raghavaiah K. A comparative study of pre-and post-menopausal breast cancer: Risk factors, presentation, characteristics and management. Journal of research in pharmacy practice $2014 ; 3: 12$.

Xia YQ, Wei XY, Li WL, Kanchana K, Xu CC, Chen DH, Chou PH, Jin R, Wu JZ, Liang G. Curcumin analogue A501 induces G2/M arrest and apoptosis in non-small cell lung cancer cells. Asian Pacific Journal of Cancer Prevention 2014; 15: 6893-6898. 